\title{
Cryptococcosis in a Cat
}

\author{
Paula Elisa Brandão Guedes', Thaís Nascimento de Andrade Oliveira², Julian Andrade Santos², \\ Mário Sérgio Lima de Lavor ${ }^{3}$, Fabiana Lessa Silva ${ }^{3}$, Luci Ana Fernandes Martins ${ }^{3}$ \& Renata Santiago Alberto Carlos ${ }^{3}$
}

\begin{abstract}
Background: Cryptococcosis is a mycosis that primarily affects domestic cats and is caused by fungi of the genus Cryptococcus, resulting in cutaneous, ocular, respiratory, and neurological manifestations. Diagnosis is based on the microscopic evaluation of the lesions and isolation of the causative agent. The aim of this study was to describe a case of feline cryptococcosis diagnosed by cytology and treated at the Veterinary Hospital of the State University of Santa Cruz (HV-UESC). Case: A 5-year-old uncastrated male cat was taken to the HV-UESC small animal clinic, owing to a gradual increase in the volume of the nasal plane spanning over a year, accompanied by respiratory distress. Upon physical examination, the animal was found to have regular nutritional status, dehydration, hypocorous mucosae, and enlarged popliteal lymph nodes. In addition, multifocal areas of ulceration on the body as well as increased volume in the nasal plane (clown nose) were observed. Peripheral blood samples were collected for complete blood count and biochemical analysis. Due to clinical suspicion of fungal lesions, fine needle aspiration of the nasal lesion was performed and cytological slides were sent to the HV-UESC histopathology laboratory. Probable diagnoses included rhinosporidiosis, cryptococcosis, and histoplasmosis. The animal was subjected to thoracic radiography in the imaging division of the HV-UESC. Blood counts revealed thrombocytopenia $\left(130,000 / \mathrm{mm}^{3}\right)$ and biochemical tests presented hypoproteinemia $(3.2 \mathrm{~g} / \mathrm{dL})$, with hypoalbuminemia $(1.52 \mathrm{~g} / \mathrm{dL})$; however, chest radiography did not show pulmonary alterations. Results of cytological analysis indicated pyogranulomatous inflammation associated with intracellular organisms, demonstrating a pathogen morphology similar to that of Cryptococcus spp. Before the diagnosis, itraconazole ${ }^{1} 5 \mathrm{mg} / \mathrm{kg}$ ( 1 capsule, twice a day for 30 days) and fipronil ${ }^{2}$ ( 1 ampoule $0.5 \mathrm{~mL}$, on the back) were prescribed. Follow-up after 40 days showed a slight improvement in cutaneous lesions and respiration, and no other abnormalities were observed. At the follow-up, the owner disclosed that medication could not be administered at the prescribed frequency because of the animal often ran away from home and stayed without prescription. Due to unsatisfactory response to the first treatment, the dosage of itraconazole ${ }^{1}$ was increased to $10 \mathrm{mg} / \mathrm{kg}$ ( 1 capsule, twice a day, for 30 days) with a new regimen and follow-up after 15 days. However, the owner did not make a follow-up visit. A year later, after several attempts to contact the owner, we were notified that the treatment had been discontinued and the cat still presents with lesions.

Discussion: Although cryptococcosis is not endemic, the cat roamed freely on the streets and may have been infected by inhaling the microorganism spores present in the environment. The clinical signs exhibited by the animal were consistent with the findings associated with Cryptococcus spp. infection in cats, especially the "clown nose" lesion. The cat, besides being dehydrated at the time of care, had a regular nutritional status. Cytology, the only diagnostic technique used in this case through which it was possible to visually identify the fungus, was definitive for the diagnosis of cryptococcosis. Although the prescribed treatment is one of the most indicated in such cases, it was not effective, possibly due to inadequate administration. The length of infection, discontinuation of therapy, and absence of follow-ups for clinical reassessment certainly contributed to an unfavorable prognosis.
\end{abstract}

Keywords: cutaneous mycosis, cytological diagnosis, Felis catus. 


\section{INTRODUCTION}

Cryptococcosis is a mycosis caused by a blastomycete of the genus Cryptococcus, whose predominant species are $C$. neoformans and $C$. gattii. Cryptococcosis mainly affects cats; however, it has also been described in dogs, goats, birds, and horses [2,6,14]. Pigeons are the main carriers in urban areas and infection occurs through inhalation of the spores dispersed in air from contaminated feces [2,7,11]. Although it is considered a zoonosis, the potential for transmission of infection from cats to humans is discussed, as yeast do not easily spread from infected tissues $[2,6,13]$.

Cryptococcosis in cats manifests as a localized or systemic disease, the main local indication of which is a granulomatous lesion in the nasal cavity, which leads to an increase in volume of the nose, popularly known as "clown nose" [2,13].

The diagnosis is based on the cytological or histopathological analysis of the lesions, isolation and culture of the agent, and/or molecular methods $[2,10]$.

Treatment consists of administration of systemic antifungal agents, with itraconazole being one of the most preferred. The disease is fatal in cases that do not receive treatment or are treated incorrectly, as well as in immunocompromised patients $[2,8]$.

Cryptococcosis is important both in veterinary and human medicine, as it is an opportunistic infection with serious and fatal complications in immunocompromised patients. In addition, although it is a common occurrence in domestic cats, the number of cases reported locally is small. The aim of this study is to report a case of cryptococcosis in a cat treated at the Veterinary Hospital of the Santa Cruz State University (HV-UESC).

\section{CASE}

A 5-year-old black-and-white male cat, weighing $3.1 \mathrm{~kg}$, was treated at a small animal clinic of the HV-UESC. The main complaint was increased nasal plane volume. According to the owner, the animal was afflicted by the injury about a year ago, presenting as a small wound that progressed over months and was treated with a topical medication without a veterinary prescription. However, the owner could not remember the name of the medication. The cat had difficulty breathing but was eating well and presented with normal urination and defecation. In addition, the owner reported that the animal roamed freely in a residential neighborhood, the municipality of Itabuna-BA and referred to the presence of bats in the roof of his house, and birds at the backyard. The cat was fed commercial food and did not possess up-to-date worming and vaccination coverage. The owner mentioned that none of the people in contact with the animal presented with any skin lesions.

Upon physical examination, the animal was found to have regular nutritional status, dehydration, hypocorous mucosae, and enlarged popliteal lymph nodes. An increase in the nasal plane volume (measuring approximately $1 \mathrm{~cm}$ in diameter) and a pink colored "clown nose" were observed (Figure 1). In addition, multifocal areas of lesions and ulceration were noted all over the body, ranging from 1 to $2 \mathrm{~cm}$ in diameter, and the animal carried fleas and presented with hypotrichosis but no areas of alopecia. Blood samples were collected for complete blood count and biochemical analysis in the laboratory of clinical analyses of the HV-UESC. Since the first clinical impression of the lesion is that it is of fungal etiology, fine needle aspiration was performed with slide preparation, and samples were sent for cytological analysis in the HV-UESC histopathology laboratory. Probable diagnoses included rhinosporidiosis, cryptococcosis, and histoplasmosis. The animal was sent for X-ray (imaging division of the HV-UESC) of the head and thoracic cavity to check if there was bone involvement and to investigate possible pulmonary involvement.

Blood counts and biochemical tests revealed thrombocytopenia $\left(130,000 / \mathrm{mm}^{3}\right)$ and hypoproteinemia $(3.2 \mathrm{~g} / \mathrm{dL})$ with hypoalbuminemia $(1.52 \mathrm{~g} /$ $\mathrm{dL}$ ), respectively. Radiograph of the head showed an increase in volume of the nasal cavity without bone involvement. The chest X-ray did not show any pulmonary changes (Figure 2). Cytology revealed a moderate cellular sample, composed of macrophages, neutrophils, and some plasma cells. Round to slightly oval organisms, measuring about $8-10 \mu \mathrm{m}$ in diameter were observed in the cytoplasm of macrophages, with eccentric purple nuclei, sometimes larger in size and with a clear halo around them (Figure 3 ). The cytological characteristics indicated pyogranulomatous inflammation associated with intracellular organisms, demonstrating a pathogen morphology similar to that of Cryptococcus spp.

Before the cytological analysis, the veterinarian responsible for the treatment prescribed itraconazole $^{1} 5 \mathrm{mg} / \mathrm{kg}$ ( 1 capsule, twice a day, for 30 days), 
and fipronil ${ }^{2}$ ( $0.5 \mathrm{~mL}, 1$ ampoule). The animal was released and a follow-up after 40 days was scheduled for re-evaluation.

During the follow-up, physical examination revealed a slight improvement in cutaneous lesions and respiration without any other abnormalities. The owner disclosed that she was unable to administer the medication at the prescribed frequency, since the animal often ran away from home and stayed without prescription. Because the first treatment response was not satisfactory, itraconazole ${ }^{1}$ was prescribed, at a higher dose of $10 \mathrm{mg} / \mathrm{kg}$ ( 1 capsule, twice a day, for 30 days). Follow-up was scheduled for 15 days later, along with a suggestion to castrate the cat. However, the owner did not bring the animal for follow-up. A year later, after several failed attempts to contact the owner, she reported that the treatment had been interrupted and the cat still presented with lesions (Figure 4).

\section{DISCUSSION}

In the present report, the cat was an adult male mixed breed, characteristics that are not related to cryptococcosis, according to the literature $[6,12]$. However, the animal was not castrated and roamed freely, thereby increasing the chances of exposure to cryptococcosis infection.

Infection with $C$. neoformans, a species most commonly involved in cats and human infections in Brazil, is associated with environmental contamination with bird feces, mainly pigeons [7,11]. The cat in this

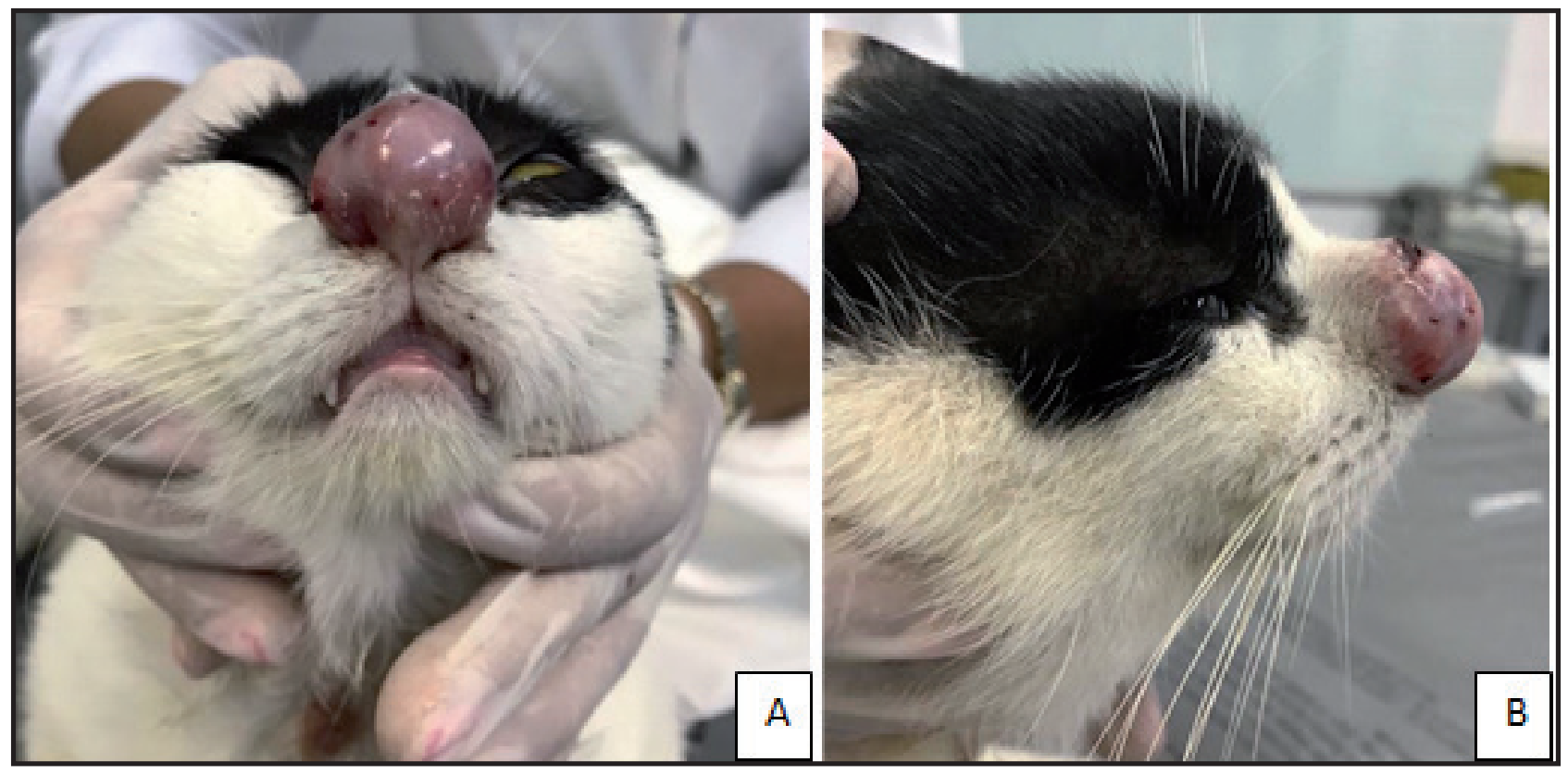

Figure 1. A \& B- Cutaneous cryptococcosis in a male, mixed breed cat. Increased volume in the nasal plane (clown nose) observed.

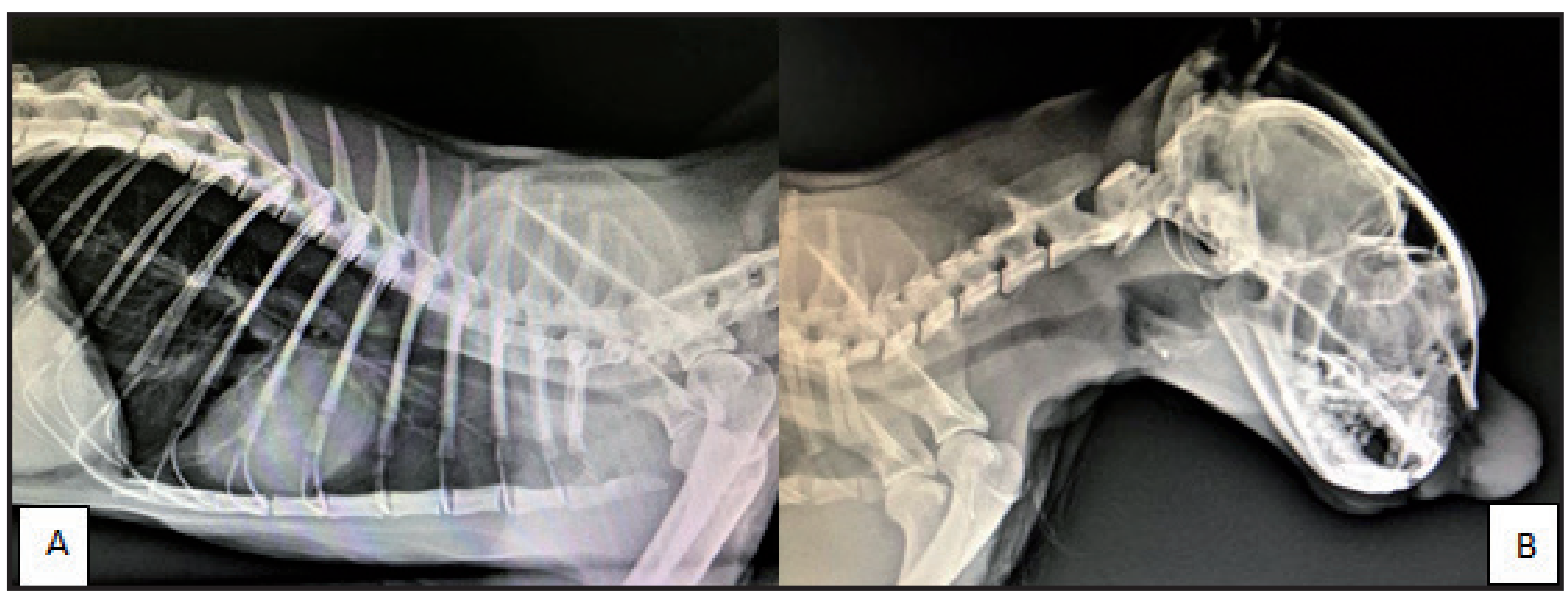

Figure 2. A- Chest X-ray of a feline (male, mixed breed cat) with cutaneous cryptococcosis. Absence of changes in the lungs observed. B- Radiograph of the head of the feline (male, mixed breed cat) with cutaneous cryptococcosis. Increased volume in the nasal plane, without bone involvement, observed. 


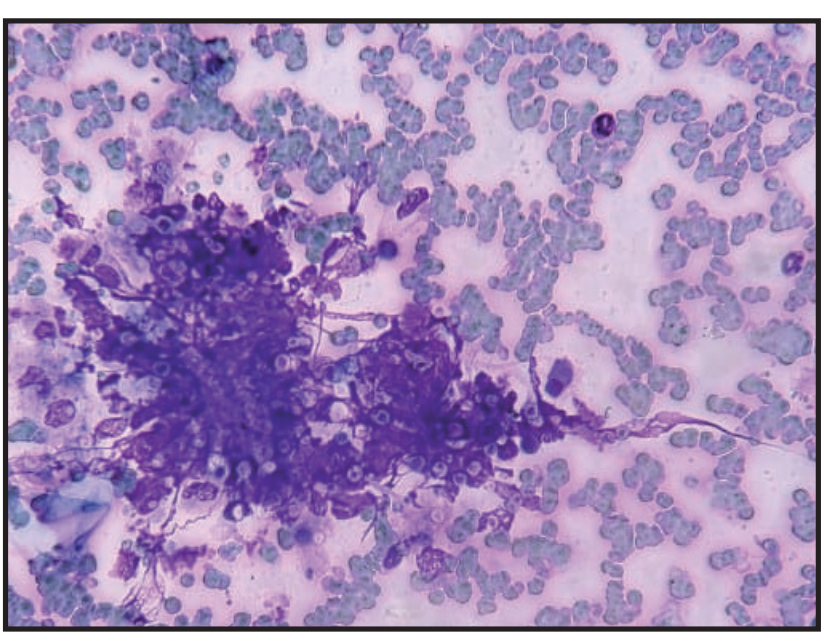

Figure 3. Fine needle aspiration of the nasal lesion of the feline (male, mixed breed cat). Round to slightly oval organisms within the cytoplasm of macrophages, measuring approximately $8-10 \mu \mathrm{m}$ in diameter, with purple eccentric nuclei, sometimes larger in size and with a clear halo around them (Cryptococcus spp.) [Diff Quick. 40x].

case report roamed freely and was possibly infected by inhaling the cryptococcosis spores present in the environment. As mentioned earlier, cases of cryptococcosis in southern region of Bahia, Brazil are uncommon, this being the only case reported in HV-UESC during the year. The low rate of occurrence could be attributed to the small cluster of pigeons and birds in urban areas, because the Ilhéus-Itabuna microregion still has large areas of forest (Atlantic Forest), the natural habitat of the vectors, thus reducing contamination of urban centers.

The clinical signs presented by the animal were consistent with the findings described in the literature in cases of Cryptococcus spp. in cats, especially the "clown nose" [2,12,14], as well as cutaneous lesions [2], thus leading to the tentative diagnosis of cryptococcosis. Nevertheless, due to the macroscopic characteristics observed, rhinosporidiosis and histoplasmosis were considered as differential diagnosis. The literature indicates that other diseases may also be considered as differential diagnosis, such as coccidioidomycosis, blastomycosis, neoplasias $[9,10]$, such as squamous cell carcinoma $[3,4]$. The observed similarity between the lesions present in these different diseases can lead to underdiagnoses of cryptococcosis in the clinical setting [9].

Although cryptococcosis is the most frequent systemic mycosis in cats [10], the localized form observed in the animal in this report is the most common in contrast to canine and human disease. This is because, in comparison to canines and humans, cats possess a more efficient air filtration system involving the mucociliary sheet of the paranasal sinuses, contributing to the removal of small inhaled particles [2]. The cat in

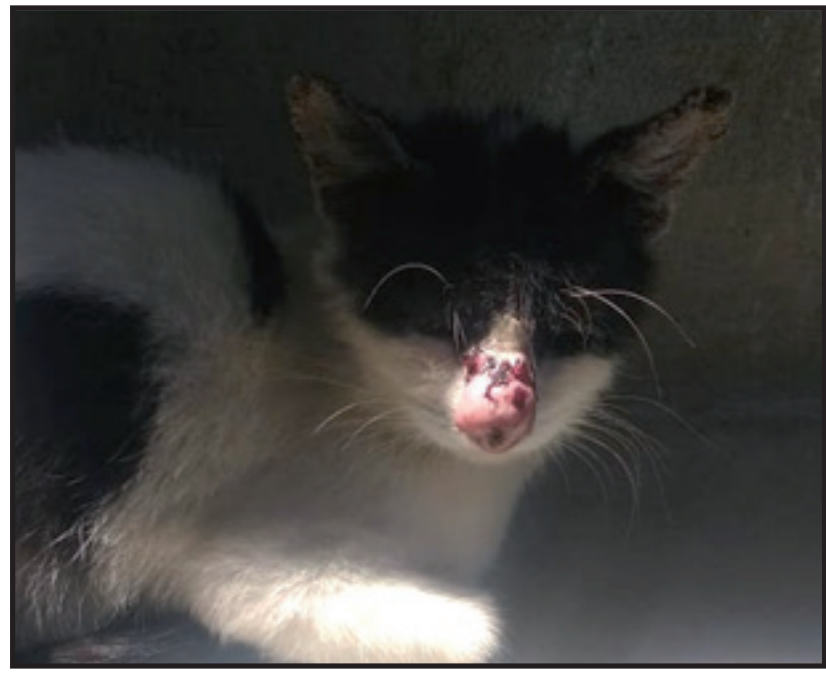

Figure 4. Cutaneous cryptococcosis in a feline (male, mixed breed cat), after interruption of treatment by the owner. Perseverance of the increased volume in nasal plane (clown nose) observed.

this case report presented only the cutaneous lesions, with no respiratory, ocular, or neurological alterations. Although the animal exhibited dyspnea, respiratory distress was attributed to edema of the nasal cavity, which may have impeded air flow. The typical clinical signs of cats affected by the respiratory syndrome, such as rales, nasal discharge, and sneezing [1], were not observed in this case. Although yeast can reach the lungs via the hematogenous route [2], no pulmonary alteration was detected by chest radiography.

The increased volume of the popliteal lymph nodes observed in the physical examination may be a nonspecific alteration, because although lymphadenomegaly is present in Cryptococcus spp., infections, the lymph nodes that are usually affected are the mandibular lymph nodes [3]. Hematological and biochemical findings were also non-specific in this study, as has been reported by Marcasso et al. [9] who described cryptococcosis in dogs.

Although cryptococcosis affects immunocompetent animals, the infection is opportunistic, and is more common in immunosuppressed cats who are undernourished, undergoing prolonged corticosteroids use, or infected with viruses such as feline immunodeficiency (FIV) and feline leukemia (FeLV) [2]. The cat in this report, apart from being dehydrated at the time of care, had regular nutritional status with hypoproteinemia, which could lower the immunocompetence of the animal and contribute to the development of clinical disease. The fact of that the cat is intact may have predisposed the animal to the disease because, during the search for females in estrus, there is a reduction in food intake and 
a reduction in immunity. No previous corticosteroid use was reported in this case. It could not be determined if the cat had any of the viral infections described above since it was not possible to perform the FIV/FeLV test. Immunosuppression is not always clear in affected cats, and cryptococcosis may manifest due to pathogenic mechanisms inherent in the causative agent [9]. One such pathogenic mechanism is that involving the polysaccharide capsule, which inhibits phagocytosis and migration of leukocytes to the lesion site, mechanisms that are important for the innate immune response.

In cases of cryptococcosis, cytological analysis is crucial for definitive diagnosis, and the microscopic characteristics observed in this study were consistent with those described in the literature [5]. In addition, the cytology results ruled out neoplasia.

Although the prescribed treatment is one of the most indicated in cases of cryptococcosis in cats, the animal, in this case, did not show significant improvement after 30 days of itraconazole therapy. Other authors have also reported no response to treatment with the prescribed drug in infected cats [13]. In the present case, however, ineffective treatment is attributed to inadequate administration of the antifungal drug, with the owner reporting that he could not administer the drug at the frequency prescribed by the veterinarian.

A lack of cutaneous lesions in people in contact with the animal suggests that cryptococcosis is not easily transmitted from cats to humans, as mentioned in the literature [6], because the spread of spores from the tissues of infected animals is rare.

Early diagnosis is crucial for a good prognosis [9]. However, the animal in question had the skin lesions for approximately a year before the first treatment, according to the owner. Infection time, treatment discontinuity, and non-adherence to follow-up for clinical assessment contributed to an unfavorable prognosis for the cat in the present report.

As the cat population rises each year, the study of diseases with zoonotic potential should be encouraged because domestic cats can act as dissipating agents of zoonoses. Thus, periodic veterinary monitoring of these animals is of great relevance, not only for animal health, but also for human health. The present case report shows one of many instances where owners neglect the role of sanitation in preventing diseases in companion animals, by discontinuing the treatment and failing to follow-up for clinical evaluation by the veterinarian.

\section{MANUFACTURERS}

${ }^{1}$ CEPAV - Centro De Patologia Clínica Veterinária. Água Branca, SP, Brazil.

${ }^{2}$ Merial Boehringer Ingelheim. Ingelheim, Germany.

Declaration of interest. The authors report no conflicts of interest. The authors alone are responsible for the content and writing of the paper.

\section{REFERENCES}

1 Aranha A.R. \& Zappa V. 2009. Criptococose. Revista Científica Eletrônica de Medicina Veterinária. VII(12): 1-4.

2 Canavari C., Vargas G.H., Tinucci-Costa M. \& Camplesi A.C. 2017. Criptococose: revisão de literatura. Revista Electrónica de Veterinária. 18(9): 1-5.

3 Castro N.B., Rolim V.M., Nascimento L.C., Silveira A.F.V., Argenta F.F., Ferreiro L., Driemeier D. \& Sonne L. 2017. Doenças micóticas em gatos no Rio Grande do Sul. Pesquisa Veterinária Brasileira. 1313-1321.

4 Correa J.M.X., Oliveira N.G.S.G., Silva F.L., Michel A.F.R.M., Lavor M.S.L., Silva E.B. \& Carlos R.S.A. 2017. O diagnóstico preciso muda o prognóstico do paciente felino com carcinoma de células escamosas? Medvep - Revista Científica de Medicina Veterinária - Pequenos Animais. 15(46): 54-60.

5 Cowell R.L., Tyler R.D., Meinkoth J.H. \& DeNicola D.B. 2009. Principais agentes infecciosos. In: Cowell R.L., Tyler R.D., Meinkoth J.H. \& DeNicola D.B. (Eds). Diagnóstico Citológico e Hematologia de Cães e Gatos. 3.ed. São Paulo: Editora MedVet, pp.47-67.

6 Danesi P., Furnari C., Granato A., Schivo A., Otranto D., Capelli G. \& Cafarchia C. 2014. Molecular identity and prevalence of Cryptococcus spp. nasal carriage in asymptomatic feral cats in Italy. Medical Mycology. 52: 667-673.

7 Faria R.O., Nascente P.N., Meinerz A.R.N., Cleff M.B., Antunes T.A., Silveira E.S., Nobre M.O., Meireles M.C.A. \& Mello J.R.B. 2010. Ocorrência de Cryptococcus neoformans em excretas de pombos na Cidade de Pelotas, Estado do Rio Grande do Sul. Revista da Sociedade Brasileira de Medicina Tropical. 43: 198-200.

8 Lima G.H., Alves E.H.A. \& Oliveira D.M. 2017. Diagnóstico de criptococose nasal em felino por meio da citologia aspirativa por agulha fina (PAAF) na região noroeste do Ceará. Ciência Animal. 27(2): 26-29. 
9 Marcasso R.A., Sierra S., Arias M. V. B., Mônica V., Bracarense A.P.F.R.L., Yakamura A.A.M., de Biasi F., Lopes B.A., Amude A.M. \& Cortês D.E.A. 2005. Criptococose no sistema nervoso de cães - relato de três casos. Semina: Ciências Agrárias. 26(2): 229-238.

10 Pereira M.F., Santos B.M., Silva V.C.L., Pereira H.N.S., Silva L.B.G., Paiva B.H.A., Barros R.B., Dias M.B.M.C., Neves A.K.R. \& Oliveira A.A.F. 2013. Aspectos clínicos e anatomopatológicos da criptococose nasal com disseminação sistêmica em cão: relato de caso. Medicina Veterinária. 7(2): 7-15.

11 Reolon A., Perez L.R.R. \& Mezzari A. 2004. Prevalência de Cryptococcus nos pombos urbanos na cidade de Porto Alegre, Rio Grande do Sul. Jornal Brasileiro de Patologia e Medicina Laboratorial. 40(5): 293-298.

12 Sanchini L., Reading M., Williams T. \& Archer J. 2017. Unusual clinical presentation of cryptococcosis in an immunocompetent cat. Veterinary Record Case Reports. e000524. doi: 10.1136/vetreccr-2017-000524.

13 Santos C.M., Tonial A.L., Duarte V.R., Favscho A.R.M., Ferreira E.C. \& Aquino D.R.R.R.A. 2018. Exposição de felinos a agentes infecciosos de interesse zoonótico. Análise molecular em gatos de Campo Grande, MS, Brasil. Brazilian Journal of Animal and Environmental Research. 1(1): 115-124.

14 Vieille P., Cruz R., León P., Cáceres N. \& Giusiano G. 2018. Isolation of Cryptococcus gattii VGIII from feline nasal injury. Medical Mycology Case Reports. 22: 55-57. 